\title{
Texturas da vida: uma filosofia para as máquinas
}

Vitor Butkus

Tania Galli Fonseca

\section{Textures of life: a philosophy for the machines}


Resumo: O problema dos conjuntos e redes técnicos, tal como singularizado por Gilbert Simondon em seu primeiro livro, constitui uma interessante via de pensamento para uma crítica e para um entendimento das atitudes produtivas, criativas e científicas da contemporaneidade. Nesse artigo, discutimos as linhas gerais desse problema, demonstrando como as noções simondonianas de tecnicidade e acoplamento se afinam com a idéia bergsoniana de uma evolução criadora. As máquinas, abordadas desde o seus modos de existência, não se reduzem à simples listagem de equipamentos mecânicos. Os objetos técnicos desenvolvem em torno de si uma temporalidade singular. Na individuação das máquinas, através da qual podemos ver a criação da realidade urbana, com seus parques industriais e indústrias do entretenimento, pode-se atentar para devires que, ganhando estruturas materiais e subjetivas para sua expressão, traçam linhas diversas das histórias já apropriadas pelo Homem.

Palavras-chave: Máquinas. Redes técnicas. Individuação. Tecnicidade. Acoplamento.

\begin{abstract}
The problem of technical ensembles and nets, as singularized by Gilbert Simondon in his first book, constitute an interesting way of thinking towards a critical understanding of productive, creative and scientific attitudes in our contemporaneity. In this article, the general lines of this problem are discussed, demonstrating how Simondon's notions of technicity and coupling are in debt with the idea of a creative evolution. Considered in their modes of existence, machines cannot be reduced to a simple amount of mechanical equipments. Technical objects are developed within a singular temporality. The concept of individuation is an important key in order to think the temporal development of these objects as a significant historical difference.
\end{abstract}

Keywords: Machines. Technical nets. Individuation. Technicity. Coupling.

BUTKUS, Vitor; FONSECA, Tania Galli. Texturas da vida: uma filosofia para as máquinas. Informática na Educação: teoria \& prática, Porto Alegre, v.10, n. 2, p.77-88, jul./dez. 2007. 


\section{Introdução}

Essa introdução, escrita por último, parece querer retomar um fio. Um fio de prumo, ou o fio da meada. Com que matéria religar uma escrita à experiência? São invisíveis - ainda, neste momento - as linhas que possam, de alguma forma, conectar as máquinas ao mundo, à música, às imagens. Linhas sem forma, talvez elas mesmas a alma e a animação desse processo de escrita.

Os hábitos citadinos, constituindo-nos enquanto habitantes, dão margem a uma experiência, da qual não só os homens participam ativamente. A convivência com os objetos técnicos nos aponta para a heterogeneidade em que se constitui uma contemporaneidade em ato.

Aproveitamos o tempo singular da escrita nem tanto para refletir sobre a experiência vivida, mas para refratá-la; para quem sabe assim, prolongar os seus efeitos. Um relato do que nos toca, enfim. Percorrendo-o, aparece-nos aos poucos a imagem de uma pele, mapeada por pontos de toque: lugares de existência, de sensibilização, e ao mesmo tempo de elaboração de conhecimentos. Uma pele com a qual nos deixamos passivamente confundir. Encontramos uma atividade qualquer, porém, na impossibilidade de nos identificarmos a ela.

Elabora-se, assim, uma conexão vital: entre um pensamento maquínico e as máquinas que utilizamos - suscitando, pelo pensamento, a proliferação das tendências criadoras que os objetos técnicos instauram, para além de sua utilidade prática. Para além de uma história das invenções técnicas, podemos pensar, contemporaneamente, desde um devir maquínico. Criar uma filosofia para as máquinas é, então, extrair da experiência mais atual as ferramentas conceituais que apontem para um vitalismo híbrido.

\section{Texturas da vida}

Na tentativa de aprofundar esse estudo das relações criativas entre homem e máquinas, encontramos em Henri Bergson (1959) uma sugestão interessante. A concepção de vida desse autor, esboçada em sua obra centenária, " $A$ evolução criadora”, nos convida a questionar a noção de vida como conservação das espécies. Abre-se a cortina de uma heterogênese, onde a vida se expressa naqueles encontros, explosivos ou sutis, que dêem margem à duração.

A vida é possível onde haja dispersão de energia (tendendo à entropia) e suportes de lentificação dessa dispersão e de acumulação dessa energia; logo, a vida é possível para além (e para aquém) das formas conhecidas. A vida em Bergson não está necessariamente contida em formas, o que nos direciona a uma busca sensível pelos focos ou campos acumulativos nos quais os fluxos de matéria, resistindo à simples dissolução, podem durar. Afirmar que a vida inaugura o tempo não seria mais coerente, portanto, que afirmar a indissociabilidade entre vida e tempo.

A vida é concebida, na falta de um melhor nome, como consciência. Aqui, cabe ressaltar que Bergson (1959) não se refere à consciência da qual o Eu é o substrato imaginado; mas a uma consciência que atravessa o sujeito. Transconsciência, da qual o homem não é o depositário exclusivo. Esta se expressa no modo de existência das plantas, dos animais, das amebas e dos vírus; dos objetos técnicos.

Outro aspecto importante na concepção bergsoniana da vida diz respeito ao movimento de diversificação das tendências. A evolução das formas de vida ramifica-se em linhas divergentes. Assim, a planta é uma extremidade evolutiva de enorme importância para a vida nas circunstâncias terrestres: só ela pode retardar a 
dissipação da energia solar, convertendo-a em substratos químicos. Entretanto, o modo de existência da planta, mesmo permitindo o acúmulo químico da energia solar, não se prolonga naquela tendência vital que consiste em recolocar a energia em trânsito.

Os animais e o homem encontram-se, assim, numa outra linha da evolução criadora: eles incorporam, em sua simples existência, a exigência de criação. Eles informam, ou seja, alimentam-se da energia armazenada; seus corpos compõem-se na direção de aproveitar essa energia disponibilizada no habitat. Aproveitando-a na conformação de sua plasticidade, geram-com ela-movimento.

Os animais são corpos móveis, capazes de deslocar a vida em muitos outros sentidos mais. Eles criam ritmos na superfície da Terra: dormem, acordam, comem, gritam, fazem bandos, copulam. Marcam territorialidades. Nesse movimento, o próprio habitat, enquanto suporte material dessas existências, devém outro. Seres em movimento executam sua música viva às vezes surdamente. Constituindo territórios, os animais fazem com que a vida não caiba em si: um sistema de relações recorrentes se cria: territorialidades vivas se deslocam, deslocando matérias.

A vida é psicológica, no sentido de que se desenvolve para atitudes livres, ou seja, para atitudes indeterminadas. Cabe aqui tentar desenvolver o sentido do psicológico e do humano em Bergson.

O humano não diz respeito a uma imagem justa, ou a uma moralidade fixa. Abolindo qualquer tipo de antropocentrismo, podemos entender em que medida o homem aparece como uma extremidade da evolução criadora. É que, no homem, a potência criadora atingiu um estado ímpar de independência em relação às coerções da matéria. Prolonga-se, nele, a capacidade de imprimir ritmos à matéria-de criar, nos limites, outras matérias.

O cérebro humano, dotado de plasticidade e propensão a aprender, equipa a máquina humana com uma margem de indeterminação bastante ampla. Em relação às outras formas de vida, o homem tem condições privilegiadas, não tanto por se adaptar melhor, mantendo-se sobrevivente como forma; mas principalmente por poder expandir a amplitude de sua ação criadora a horizontes com limites indeterminados.

O humanismo de Bergson (1959), assim, só é pensável como abertura aos devires criadores e trans-humanos. E a cerebralidade que aí é invocada não é aquela de uma Razão em oposição ao instinto animal, mas à possibilidade de que, no homem, os fluxos possam durar, na forma de novos a prioris. Pensamento, imagens em movimento.

\section{Humanismos e maquinações}

Aqui se escuta uma ressonância entre os humanismos de Henri Bergson (1959) e de Gilbert Simondon (1989). Ao revisar os discursos técnicos, nos quais se pode adivinhar uma história da relação homem-máquina, Simondon detém-se no enciclopedismo, tido por ele como modo de agregar os inventos técnicos no horizonte da transmissão cultural.

O homem renascentista, aprimorando os elementos técnicos herdados da cultura grecoromana, manejou-os então na criação da perspectiva. A geometria praticada na representação perspectivista ilustra uma virada antropológica a partir da qual o homem, manipulador de elementos técnicos criados por seus ancestrais, pôde se representar como sujeito do olhar.

Espelhado, ao inverso, pelo ponto de 
fuga único, o homem renascentista padroniza uma maneira de representar os objetos, a partir de uma técnica que implica também um posicionamento de si no mundo. Foi esse o contexto tecno-existencial que presenciou o surgimento do artista e a individuação da própria arte como disciplina. Alberti e Leonardo são figuras exemplares aí, tanto no procedimento técnico do desenho, quanto na teorização artística. A arte, feita disciplina, delimita, ao modo clássico, uma série de normatizações. Surge, com a figura do artista, um lugar socializado para a arte, enquanto prática específica.

Entre as linhas perspectivas e os rostos dos padres e das aristocracias, ganham existência seres de sensação, entabulados nos interiores de molduras. Acompanhar a arte no frescor da emergência de tais configurações técnicas e sociais nos permite, pelo menos, suspeitar que as tranversalidades entre a criação artística, as técnicas e os lugares sociais que lhe são contemporâneos, não são tão recentes quanto podem parecer.

A tipografia, desenvolvida no século XVII, vai possibilitar um novo enciclopedismo. A geometria euclidiana, naturalizada pelas práticas artísticas e científicas desde o Renascimento, será o instrumento da produção de um saber sobre os elementos técnicos disponíveis. A técnica tipográfica, passível de reprodutibilidade, modula a experiência técnica, oferecendo um acesso mais amplo aos elementos e balizando um novo modo de iniciação nos modos de existência dos objetos técnicos (SIMONDON, 1989, p. 98). É interessante que, aqui, o autor já nos chama a atenção para uma mudança na relação homem-máquina que é potencializada pela própria evolução técnica das mídias.

Os enciclopedismos deram a ver, em cada momento histórico, a continuidade da ex- periência humana nas máquinas. Assim, a sua leitura dos iluministas nos mostra a aventura descritiva que, então, tinha como objeto os elementos técnicos. A Enciclopédia explica o funcionamento de cada máquina tomada nesse nível, chamado, por Simondon (1989), de elementar.

A peculiaridade da narrativa simondoniana capta, na seqüência, uma descontinuidade que passa a ser levada em conta na sua filosofia para as máquinas. Nos séculos XVIII e XIX, percebem-se um aumento e uma complexificação na interação entre os elementos técnicos. Formam-se vínculos entre as matérias mecânicas, uma peça exige, para funcionar, que outra peça funcione. Essas outras máquinas, para existirem, fazem com que exista um meio associado, que se estende sobre a geografia natural e humana. Num nível em que as máquinas fazem cultura, elas mediam o surgimento das cidades, apontando inclusive os melhores lugares para a fundação de povoados - junto aos focos de carvão, às estradas de ferro ou às linhas energéticas.

Detecta-se aí uma nova fase da evolução técnica; individuando-se, as máquinas criam territórios. Como os animais de Bergson, os objetos técnicos criam à sua volta um novo ritmo de vida. E os homens, seus contemporâneos, reagindo a isso, não nos deixam faltar testemunhos: poemas românticos, mitos do bom selvagem, sindicalismos a planejar, pela destruição das máquinas, a volta de um estado deixado pra trás. Todos esses traços, encravados na história da cultura, apontam para uma transformação da experiência humana, e também para uma modulação dos seres-máquina em seu processo de individuação.

Os modos de existência das máquinas, abordados dessa forma, permitem que não nos deixemos levar pela simples listagem de equipamentos mecânicos, tomados sobre uma linha 
cronológica. O surgimento de realidades técnicas precisa ser tomado, de outra parte, como modulação da vida que se processa, acoplada às técnicas. Na individuação das máquinas, através da qual podemos ver a criação da realidade urbana, com seus parques industriais e indústrias do entretenimento, pode-se atentar para devires que, ganhando estruturas materiais e subjetivas para sua expressão, traçam linhas diversas das histórias já apropriadas pelo Homem.

\section{Seres do acoplamento}

Humanizar a relação homem-máquina, assim, não significa imprimir sobre a máquina uma forma-homem. Contemporâneo aos inícios da cibernética, o livro Du mode d'existence des objets techniques clama por atitudes que tomem as máquinas do presente como linhas divergentes de uma criação sem fim. Simondon (1989) apresenta-nos a uma contemporaneidade que já não é aquela dos indivíduos técnicos, mas aquela dos conjuntos, das redes dinâmicas, cuja realidade escapa a objetificações e idealizações bem estruturadas. Num esforço convergente ao de Bergson (1959), nos primeiros capítulos de sua $A$ evolução criadora, Simondon faz uma crítica a modos de pensar herdeiros de uma configuração ultrapassada pela heterogeneidade dinâmica vivida em nosso presente. A inteligência, modo de pensamento individualizado por excelência, merece algum reproche crítico.

Assim como a consciência criadora não se confunde com aquela do indivíduo, o indivíduo humano não se faz prolongamento da vida pela sua inteligência. Bergson (1959) pensa criticamente a civilização, em seus modos de pensar e agir, ao escrever que, no homem ocidental, a consciência é sobretudo inteligência. Enquanto representação da matéria bruta, a inteligência segue o sentido inverso da potência criado- ra. A inteligência das representações tende ${ }^{1} a$ espacializar; ora, por esse caminho a criação vital é detida: como que colocada em suspenso.

A intuição é evocada justamente para tirar a vida do homem de seu estado de suspensão inteligente. Para, de certa maneira, inutilizar a ambição antropomorfizante, e dar lugar, no homem, à duração como dimensão temporal criadora de novos mundos. Para Bergson (1959), a criação, através do homem, se dá na zona de tensão entre a inteligência e a intuição.

Assim, lemos em Simondon (1989) que, imerso no estágio técnico dos conjuntos, um homem pode muito bem sobreviver inteligentemente, adaptando as técnicas às suas necessidades mais básicas. Mas, ocupado com uma ética que não se contenta com a inerte sobrevivência, ele apela a uma outra forma de pensar e agir, das quais podem-se traçar agora algumas linhas.

A inserção da realidade técnica na cultura pode se efetuar, contemporaneamente, de uma forma diferente de enciclopedismos elementarizantes, através de pensamentos e produções culturais que tomem o partido da realidade presente. Para isso, talvez não seja suficiente o acesso de todos às novidades tecnológicas, já que, na abordagem que seguimos, o que está em pauta não é uma tecnologia colocada como ápice de uma civilização, mas sim os modos como os acoplamentos se inventam, desterritorializando tanto homens quanto máquinas.

A ferramenta, o instrumento, a máquina isolada se deixam perceber por um sujeito que permanece distanciado deles. Mas o conjunto técnico só pode ser apreendido por intuição, pois ele não se deixa considerar como um objeto distanciado, isolado, abstrato, manipulável, à disposição do homem. Ele corresponde a uma experiência de existência e a um colocar-se em si- 
tuação; ele está ligado a uma ação recíproca com o sujeito. (SIMONDON, 1989, p. 228).

Como numa viagem, em que se experimenta a vivência de um lugar estranho, buscando reconhecer os valores culturais que o fundam, a imersão num conjunto técnico envolve o indivíduo nos ritmos de um ambiente, colocando "[...] o homem na presença e no interior de uma série de ações e processos que ele não dirige sozinho, mas dos quais ele participa" (SIMONDON, 1989, p. 228). Trata-se de um processo de desindividualização em que, para viver a situação do conjunto, o corpo é convocado a uma criação de si nos estados em que as potências não pertencem nem mais ao corpo, e nem à máquina, dando lugar a uma vida híbrida.

A noção de acoplamento homem-máquina, no contexto contemporâneo aos conjuntos técnicos, faz a evocação do conjunto maquínico como multiplicidade rítmica e do homem como aquele que é definido não por uma forma, mas por um território. Um conjunto técnico pode ser abordado a partir das diversas velocidades, que seriam a própria natureza desse conjunto, para além dos próprios mecanismos. Um homem, pensado no acoplamento, tem sua consistência territorial abalada. $\mathrm{O}$ acoplamento é um terremoto, em que os ritornelos que dão consistência à vida se põem a ressoar num ambiente que já é formado de ritmos e velocidades.

\section{Contratempo: Jean Baudrillard e o sistema dos objetos}

A ética de Simondon (1989), ao lançar um apelo à criação de uma nova relação com as máquinas (de um novo humanismo), convoca àquela continuidade criadora através da qual os objetos técnicos carregam-se da potência de uma temporalidade singular. Assim, a alienação sentida pelo autor refere-se a um uso da técnica escravizado por uma economia da temporalidade avessa a essa potencialidade criativa.
No livro "O sistema dos objetos", Jean Baudrillard (2006) toma essa alienação como enfoque principal. De certa maneira, ele começa o seu estudo do ponto que Simondon (1989) prefere deixar, criticamente, de lado. $\mathrm{O}$ assunto de Baudrillard é a contemporaneidade dos objetos técnicos enquanto objetos de consumo. Ou seja, a maneira como os objetos são colocados numa situação de submissão num sistema cultural. Baudrillard parte do fechamento cultural a esse devir técnico que Simondon quer fazer aparecer. Tomadas como mônadas, fechadas em $\mathrm{si}$, ou subjugadas a um funcionamento que visa a manutenção de um certo bem-estar (burguês, dirá Baudrillard), as máquinas são colocadas numa espécie de corredor fechado.

Tanto Baudrillard como Simondon concordam que uma máquina é um objeto que incorpora, na sua própria materialidade, um sistema de recorrências e determinações. Esse é o domínio mecânico, aquele que gera os resultados mais atuais e urgentes. É por aí que uma máquina produz, seja esse produto o congelamento de uma comida, uma embalagem plástica ou a execução de um CD. Conviria aqui tomar esse domínio mecânico como a atualidade da máquina. Porém, essa aparente objetividade se esfuma à medida que os dois autores vão priorizar o gestual que a própria objetividade das máquinas expressa.

O livro de Baudrillard (2006) diagnostica toda uma fantasmagoria a envolver, como uma nuvem estática, os objetos técnicos no contexto histórico das sociedades capitalistas pós-Segunda Guerra. O modo de funcionamento dessas sociedades se mantém através de um sistema simbólico forte o suficiente para sobreviver ao desmantelamento dos ideários modernos (molares) e das narrativas de origem e progresso que os sustentaram. Assim, conforma-se uma paisagem em que os objetos técnicos, ao 
fazerem-se úteis na vida cotidiana, simbolizam a eficiência da inteligência humana no controle da matéria. Sobrecarregando a sua utilidade infalível com sentidos que invocam imagens de sucesso e bem-estar, o sistema dos objetos coloca um ponto final na história. A imagem estática de um homem tem seu poderio atestado pela funcionalidade mecânica de incontáveis bugigangas. A esse homem, dissociado da potência de durar, resta colecionar os itens de uma coleção infindável.

O sistema se retroalimenta, serializando, mais do que simples objetos, promessas de completude. Dirigidas a uma forma-homem, tais promessas concretizam-se em variações técnicas: um motor sem ruído, uma alça emborrachada, um tecido que não retém suor. Remetendo à leitura de Simondon, Baudrillard (2006) se refere a essas variações como inessenciais. Inessenciais, porque estão (também elas) dissociadas de um devir técnico que se poderia expressar na criação de objetos que traçassem divergências em relação à clausura atual.

Somos mais sensíveis à perturbação da relação humana pela intervenção absurda e totalitária da técnica e menos à perturbação da evolução técnica pela intervenção totalitária e absurda do humano. (BAUDRILLARD, 2006, p. 125)

Para Baudrillard, as primeiras décadas do século $X X$ presenciaram uma riqueza inventiva ímpar, materializada em invenções importantes: o automóvel, o avião, o refrigerador elétrico, até a televisão. A partir dos anos 50 , porém, as invenções significativas teriam sido estancadas, tendo se estabilizado, em contrapartida, um sistema comercial disposto a espetacularizar pequenas modificações das mesmas. Assim, surgem os carros com rabo-depeixe, populares nos anos 60 , agregando à carroceria formas aerodinâmicas que, sem nenhuma funcionalidade técnica, remetiam a um ideal de velocidade insuperável. "Esta comédia da eficiência espontânea e transcendente do objeto requer imediatamente símbolos naturais: 0 automóvel se atavia de asas" (BAUDRILLARD, 2006, p. 65). Com esse exemplo, mostra-se de que modo a evolução técnica fica enclausurada num sistema cultural e produtivo que tem na reprodutibilidade da forma-homem a garantia de sua continuidade, através de pequenas modificações reguladas pela moda.

A paisagem descrita por Baudrillard (2006) mostra-nos máquinas orquestradas para uma imensa platéia de indivíduos. Seguindo a leitura acústica que viemos fazendo da filosofia bergsoniana, podemos ouvir aí a produção serial de centros de ressonância, pulverizados pelas cidades do mundo. Produção para a qual as tecnicidades acabam concorrendo. Como se aquele ser humano, considerado ápice de uma evolução criadora, tendesse agora a se ocupar exclusivamente da administração inteligente da matéria mecanizada.

\section{6 Áudio e vídeo na contempora- neidade dos conjuntos}

Ora, a apropriação bergsoniana do evolucionismo em voga no tempo de sua escrita nos leva justamente a questionar essa tendência. Uma leitura atual da Evolução Criadora nos dá as ferramentas para uma outra escuta da atualidade. Bergson descreve a ambição racionalizante do homem ocidental como uma tendência de certa forma contrária à inventividade que, para ele, colocaria o homem num limite extremo da fábrica viva da Terra. Compartilhando do seu intuito de ouvir "[...] na duração o estofo mesmo da realidade" (BERGSON, 1959, p. 161), finalizaremos esse escrito buscando, numa prática criativa, um amparo movente.

Na sua convocação ética a um novo humanismo, e nas linhas que já pôde traçar para 
os modos desse humanismo para o tempo presente, Simondon (1989) cria horizontes interessantes para a abordagem dos processos criativos desenvolvidos na chamada arte contemporânea. Principalmente a partir dos anos 60 do século passado, a figura do autor passou por questionamentos tanto práticos quanto teóricos. No terreno das artes, parece que aquela autonomia, conquistada no Renascimento, do artista como criador, e da arte como disciplina, sofreu abalos sérios. Uma nova onda de atitudes artísticas obrigou a historiografia das artes a reconhecer uma descontinuidade (MILLET, 2000), e a estruturação de uma plataforma metaestável doravante denominada arte contemporânea.

As atitudes de Lygia Clark e Hélio Oiticica, por exemplo, vão no sentido de uma dissolução de fronteiras, em que a arte, pelas vias da participação do público e da desmaterialização da obra, contamina-se das matérias cotidianas. $O$ artista pode se tornar o propositor de procedimentos numa complexidade cultural pós-individual, em que o acoplamento com as máquinas sociais em atividade constrói a cartografia de pontos notáveis.

Apontar para a vida ali onde ela pode durar é uma atitude de resistência criativa, numa atualidade em que não parecem faltar as condições técnico-científicas para subordinar o tempo ao espaço. Paralelamente às defasagens dos modos de existência individual do objeto técnico em modos de existir dos conjuntos, podem-se acompanhar transformações importantes no fazer artístico. Aqui, vão ser focalizados âmbitos da criação artística que existem em relação íntima com a realidade técnica: a música e o vídeo.

Na música, pode-se acompanhar uma transformação importante, ocorrida nesse século que recém passou. O contexto técnico da criação musical, à época das grandes obras clássicas, envolvia a figura do compositor na criação de partituras. A ele cabia a composição de arranjos e andamentos, que eram anotados para, num segundo momento, serem lidos e executados por uma orquestra. Aos instrumentistas, cabia a leitura e o estudo das partituras, processos nos quais se fazia uma interpretação da partitura com vistas a executar aquilo que tinha em mente o compositor. As platéias escutavam essas obras, creditando os devidos méritos ao compositor, autor da peça, e aos instrumentistas, seus executantes. Numa época anterior ao disco de vinil, a experiência musical estava ligada a esses intervalos interpretativos: dos instrumentistas em relação aos intuitos do compositor, e da platéia em relação a esses dois planos.

A experiência da arte musical passava por esses processos numa época histórica em que não se dispunha de tecnologias de gravação. Mesmo a música popular produzia-se e experimentava-se através desses procedimentos, os quais não colocaríamos em destaque se a sua transformação não trouxesse, a partir de um novo contexto técnico, outras modalidades de criação e de escuta musicais.

A Tomas Edison se credita a invenção do fonógrafo, máquina que, nos anos 1870 , serviu primeiramente para registrar acordos comerciais. Já em 1899, os primeiros discos eram lançados pela Columbia Records, contendo gravações de artistas contratados por essa gravadora; os primeiros anos do século XX já ouviam soar as jukeboxes. Nos anos vinte, uma indústria fonográfica nutria as music halls das metrópoles do mundo.

Surgiam, com isso, formas de recepção musical impensáveis antes que as máquinas de reprodução sonora fossem inventadas. $\mathrm{O}$ compositor eletrônico Brian Eno ([1979?]) diagnostica aí uma transformação na escuta, mediatizada pelos vinis, definitiva para a música no século $X X$. Num concerto gravado, a atenção da escuta pode 
se deter em detalhes que passavam despercebidos. Os eventuais virtuosismos - ou erros - dos instrumentistas vinham à tona numa escuta passível de repetição. Eno chega a dizer, assim, que manifestações como o jazzse produziram graças a esse novo ambiente que possibilitava a gravação e a reprodução.

Acredito que, de certa maneira, a gravação criou o jazz. O jazz foi, de 1925 em diante, um gênero gravado, e de 1935 em diante [...] foi um gênero que a maioria das pessoas recebia via discos. Então, estava-se ouvindo, cem vezes, coisas que foram, uma vez, somente improvisações, e estava-se ouvindo esses detalhes como sendo composicionalmente importantes. (ENO, [1979?]).

Ficando-se atento aos devires que a música do século XX manifestou, e considerandose o devir como estofo da realidade, a correr nos subterrâneos e intermezzi das disciplinas socialmente reconhecidas, torna-se possível pensar uma outra história das músicas. Uma história que não se restrinja a um saber musicológico ou historiográfico restrito ao campo musical. De fato, importantes compositores testemunham, nas ocasiões em que lhes é dada a palavra, mudanças decisivas nos modos de compor, em relação à clássica notação em partitura.

Tranversalizar a atenção, percorrendo as novas dinâmicas sociais de escuta e criação, permite, além do descarte de dualidades paralisantes (música erudita/música popular, alta e baixa cultura), uma experiência mais rica das musicalidades em curso. Entre essas dinâmicas, as retículas técnicas em que está imerso o artista parecem constituir uma interessante via de estudo da música contemporânea. O esforço de Simondon (1989), nessa leitura, nos impulsiona para horizontes de pesquisa que não poderão ser concluídos neste escrito, mas que nos anima a suspeitas preliminares.

Por exemplo. Considere-se a prática dos djs. Poucos deles lêem partituras. A matéria de trabalho de um dj consiste de faixas de áudio, gravadas em suporte digital. A combinação intuitiva dessas amostras é o que acaba gerando a música. Ou seja, não há mais aquele esquema de intervalos interpretativos, entre compositor e instrumentistas. O dj trabalha com amostras, muitas vezes criadas por outras pessoas, e muitas vezes criadas no próprio ambiente tecnológico. Os timbres de uma música eletrônica não remetem a instrumentos tocados pela mão humana, pois são elementos que resultam de acoplamentos com o suporte digital, que permite a modulação das freqüências e dos tempos.

Esse modo de trabalhar, compartilhado por inúmeros compositores nos dias de hoje, tem sem dúvida a sua história. Uma história que é a história da música no século $X X$, a história da contaminação dos modos de escuta pelo exterior. Daí a felicidade do seguinte trecho de Simondon:

[...] através das redes técnicas, o mundo humano adquire um alto grau de ressonância interna. As potências, as forças, os potenciais que impelem à ação existem no mundo técnico reticular como eles poderiam existir no universo mágico primitivo: a tecnicidade faz parte do mundo, ela não é apenas um conjunto de meios, mas um condicionamento de ações e de princípios de ações; a ferramenta ou o instrumento não tem poder normativo porque eles estão permanentemente à disposição do indivíduo; as redes técnicas detêm mais poder normativo visto que a ressonância interna da atividade humana é maior através das realidades técnicas. (1989, p. 221).

Imagine - tomando o trecho bem ao pé da letra, e subvertendo um pouco o seu sentido original -imagine o processo de tal aumento de ressonância interna, ao tempo do surgimento de conjuntos aptos a gravar os sons territoriais, distribuí-los e executá-los repetidas vezes... Rodrigo Fonseca e Rodrigues (2005) chama 
atenção, num interessante estudo sobre a música eletrônica, para a paisagem sonora urbana, um ambiente acústico criado pelas máquinas e pelas vidas que animam as cidades.

O vitalismo de Bergson (1959), ressoando na postura afirmativa de Simondon (1989), pode, assim, ser recebido como um convite a abrir os ouvidos para as intensidades sônicas que percorrem a cidade contemporânea. A música eletrônica, que já se anunciava nos procedimentos concretos de Pierre Schaeffer, nos anos 60, cria hoje outras platéias, outras modalidades de escuta e de criação. Com Deleuze, podemos nos perguntar por aquilo que dura, dentre essas novas criações. Para além da escuta e dos procedimentos de criação, que afectos atravessam os perceptos expressos nas obras? Que temporalidades inumanas podem devir na sopa acústica contemporânea?

Ao vídeo, então. A já tradicional história dessa mídia nos conta que sua manifestação como arte data dos anos 60 (novamente esses tempos...), época do lançamento das primeiras câmeras analógicas acessíveis ao grande público. De lá para cá, a videoarte tomou certa consistência, notadamente a partir do desenvolvimento das tecnologias digitais de captação e edição de imagens.

Deixando em suspenso as datas arroladas na historiografia, vamos nos concentrar naquilo que parece mais interessante para esta discussão. Pois talvez, para pensar a criação, não seja tão necessário inventariar a progressão dos instrumentos tal como ela incidiu na cronologia dos homens, quanto adentrar na história retida no nosso presente enquanto criadores e participantes vivos do devir.

Em meio a que fluxos, e inserido em quais conjuntos, atua um videasta hoje? Para além da individualidade de tal ou tal equipamento, interessa os processos gerativos, dos quais essas individuações são expressão, e os quais compõem o ambiente de criação. Uma primeira linha de abordagem nos leva a considerar a natureza das imagens digitais. A diferença dessas imagens em relação às imagens analógicas nos permite traçar o percurso de um processo de diferenciação.

A imagem analógica, captada em películas de filme, remete ao funcionamento da máquina fotográfica. Ali, a luz, passando por um conjunto de lentes, cria no filme um análogo dos objetos-referência antepostos à câmera. Isso se dá por um processo físico-químico, em que a luz refletida pelos objetos-referência sensibiliza a película, quimicamente preparada. Cada ponto da imagem analógica corresponde a um ponto da referência. Guarda-se uma semelhança.

A captação da imagem digital lega da tecnologia analógica alguns elementos, como as lentes. Porém, a luz, penetrando na máquina digital, sofre um processo de codificação numérica. Os resultados dessa codificação não se suportam mais na materialidade de uma película; eles são imateriais. A luz não opera mais uma transformação química; ela serve, em suas freqüências de cores, como variável para a criação de dados numéricos, que são armazenados nos respectivos suportes de informação (DVDs, HDs, fitas digitais). A imagem digital vai surgir quando esses dados armazenados forem transformados em informação visível. O final desse processo é uma imagem formada por pontos luminosos: os pixels.

Da descrição desse processo, podem-se depreender os pontos de atuação do videasta. Esses pontos correspondem às margens de indeterminação do conjunto em questão, ou seja, lugares de criação em que os esquemas automáticos da máquina se abrem ao acoplamento com outras máquinas ou com o 
homem. Um primeiro ponto seria o da captação da imagem. Ele envolve desde a escolha daquilo a ser filmado, até os movimentos de câmera realizados. Cabe ressaltar que essas escolhas já vêm contaminadas pela configuração da própria máquina. Câmeras com pouca sensibilidade a luzes fracas produzem imagens vacilantes em ambientes pouco iluminados. Movimentos bruscos de mão criam imagens embaralhadas, se a câmera usada é programada para receber menos variações móveis.

A edição das imagens pode começar assim que os dados numéricos forem transmitidos para um computador. São esses dados que, na edição, serão transformados. O videasta tem aí, uma ampla margem de experimentação. A edição digital é, assim, o momento em que esses dados, transferidos da câmera que os produziu, são reunidos num ambiente que pode, neles, operar mudanças. O computador é um não-lugar onde o material, deslocado de seu contexto específico, pode variar, com ampla margem de indeterminação. Novos ambientes podem surgir no trabalho dessas imagens; ambientes semelhantes ou diversos daqueles em que elas foram geradas.

Esse rápido esboço serve, aqui, para apontar a dimensão viva da criação artística junto aos conjuntos técnicos. De certa forma, esse contexto nos reenvia às texturas da vida de que falava Bergson (1959), quando tratava de captar a vida ali onde ela ainda não tem forma, ali onde ela se gera movimentando a matéria e fazendo-a sair de si. Desfeitos de automatismos utilitaristas (ou subvertendo-os, ao fazê-los acoplarem-se a um pouco de vida), temos já motivos de sobra para intuir a continuidade diferenciante que nos cria para o presente.

Notas

1 Ver, principalmente, o capítulo III, intitulado "Da significação da vida. A ordem da natureza e a forma da inteligência".

\section{Referências}

BAUDRILLARD, J. O sistema dos objetos. São Paulo: Perspectiva, 2006.

BERGSON, H. L'évolution créatrice. Paris: Les Presses Universitaires de France, 1959.

ENO, B. The studio as a compositional tool. [S.I.: s.n., 1979?]. Disponível em: <http:// music.hyperreal.org/artists/brian_eno/interviews/downbeat79.htm> Acesso em: 20 jul. 2007.

MILLET, C. A arte contemporânea. Lisboa: Instituto Piaget, 2000.

RODRIGUES, R. F. Música eletrônica: a textura da máquina. São Paulo: Annablume, 2005.

SIMONDON, G. Du mode d'existence des objets techniques. Paris: Aubier, 1989.

Recebido em junho de 2007

Aceito para publicação em outubro de 2007

Vitor Butkus

Graduando do Instituto de Artes da UFRGS vitorag@uol.com.br

\section{Tania Galli Fonseca}

Docente do Programa de Pós-Graduação em Psicologia Social e Institucional (PPGPSI) e do Programa de Pós-Graduação em Informática na Educação (PPGIE) da Universidade Federal do Rio Grande do Sul (UFRGS). tfonseca@via-rs.net 